\title{
Association between blood pressure, inflammation and spirometry parameters in chronic obstructive pulmonary disease
}

\author{
Sulhattin Arslan ${ }^{1}$, Gürsel Yildiz ${ }^{2}$, Levent Özdemir ${ }^{3}$, Erdal Kaysoydu ${ }^{1}$, and Bülent Özdemir ${ }^{4}$
}

\author{
${ }^{1}$ Department of Chest Diseases, \\ Faculty of Medicine, Cumhuriyet \\ University, Sivas; ${ }^{2}$ Division of \\ Nephrology, Department of Internal \\ Medicine, Faculty of Medicine, Okan \\ University, Istanbul; ${ }^{3}$ Department of \\ Public Health, Faculty of Medicine, \\ Cumhuriyet University, Sivas; \\ ${ }^{4}$ Department of Cardiology, Faculty \\ of Medicine, Uludag University, \\ Bursa, Turkey
}

\author{
Received: August 17,2017 \\ Revised : October 30, 2017 \\ Accepted: February 19, 2018 \\ Correspondence to \\ Gürsel Yildiz, M.D. \\ Division of Nephrology, Depart- \\ ment of Internal Medicine, Faculty \\ of Medicine, Okan University, \\ İçmeler Mah., Aydınlı Yolu Cad., \\ Aydemir Sk. No. 2, Istanbul 34947, \\ Turkey \\ Tel: +90-5055422909 \\ Fax: +90-5055422909 \\ E-mail: drgursel@yahoo.com
}

Background/Aims: Many systems including the cardiovascular system (ischemic heart diseases, heart failure, and hypertension) may act as comorbidities that can be seen during the course of chronic obstructive pulmonary disease (COPD). Comorbidities affect the severity and prognosis of COPD negatively. Nearly $25 \%$ of patients with COPD die due to cardiovascular diseases. In this study, we aimed to evaluate the relationship between the blood pressure, inflammation, hypoxia, hypercapnia, and the severity of airway obstruction.

Methods: We included 75 COPD patients in the study with 45 control cases. We evaluated age, sex, body mass index, smoking history, C-reactive protein levels, 24-hour ambulatory blood pressure Holter monitoring, arterial blood gas, and respiratory function tests of the patient and the control groups.

Results: In COPD patients, the night time systolic, diastolic blood pressures and pulse per minute and the mean blood pressures readings were significantly elevated compared to the control group $(p<0.05)$. In the correlation analysis, night time systolic pressure was associated with all the parameters except forced expiratory volume in 1 second $\left(\mathrm{FEV}_{1} \%\right)$. Diastolic blood pressure was associated with $\mathrm{pH}$ and $\mathrm{HCO}_{3}$ levels. The mean night time, day time pulse pressures and 24hour pulse per minute values were also associated with all the parameters except $\mathrm{FEV}_{1} \%$.

Conclusions: In this study we found that parameters of systolic and diastolic blood pressures and pulse pressures were significantly elevated in COPD patients compared to the control groups. Blood pressure was associated blood gas parameters and inflammation parameters in COPD patients. This, in turn, may cause understanding of the pathophysiology of COPD and its complications.

Keywords: Blood pressure; Pulmonary disease, chronic obstructive; Hypoxia; Inflammation

\section{INTRODUCTION}

Chronic obstructive pulmonary disease (COPD) is a lung disease characterized by chronic obstruction of lung airflow that interferes with normal breathing and is not fully reversible. The most common symptoms of COPD are breathlessness, or a 'need for air,' excessive sputum production, and a chronic cough. However, there is a tendency to accept the conclusion that COPD can no longer be considered as a disease affecting only the 
lungs. Increasing evidence supports the presence of a systemic inflammatory component which is thought to provide the link between COPD and the comorbidities commonly associated with this disease. These include cardiovascular disorders, skeletal muscle dysfunction, diabetes, and osteoporosis [1].

It is estimated that 64 million people suffered COPD worldwide in 2004. Systemic inflammation has a particular role in COPD pathogenesis. This inflammation is parallel to the deterioration of pulmonary functions secondary to chronic airway inflammation. Circulatory proinflammatory cytokines, C-reactive protein (CRP) as a derivative of these cytokines are important markers of systemic inflammation $[2,3]$. COPD affects various domains of lung structure and function, leading to airflow limitation.

COPD is a preventable and treatable disease characterized by airflow limitation that is not fully reversible. The airflow limitation is usually progressive and is associated with an abnormal inflammatory response of the lungs to noxious particles or gases, primarily caused by cigarette smoking. Although COPD affects the lungs, it also produces significant systemic consequences. COPD affects not only the lungs but other systems of the body as well causing different pathologies. Many systems including the cardiovascular system (ischemic heart diseases, heart failure, and hypertension) may act as comorbidities that can be seen during the course of COPD. Comorbidities affect the severity and prognosis of COPD negatively. Nearly $25 \%$ of patients with COPD die due to cardiovascular diseases $[4,5]$.

Cardiovascular disease is a significant cause of mortality in COPD, and the concepts of an inflammatory link raise the possibility that treatment for one organ may show benefits to comorbidities in other organs. When considering treatment of COPD and its comorbidities, one approach is to target the pulmonary inflammation and hence reduce any 'overspill' effect of inflammatory mediators systemically as suggested by the response to inhaled corticosteroids. Alternatively, treatment targeted towards comorbid organs may alter features of pulmonary disease as statins, angiotensin converting enzyme inhibitors and peroxisome proliferator activated receptor agonists may have beneficial effects on COPD by reducing exacerbations and mortality [6].

There is a high prevalence of common risk factors in the COPD/coronary artery disease patient population including smoking, sedentary lifestyle, and low socioeconomic status. However, various studies have shown that airflow limitation is an independent risk factor for cardiovascular diseases. Chronic low grade systemic inflammation, oxidative stress and increased platelet activation have been widely reported as being pathophysiological links between COPD and atherosclerosis. Statins and inhaled corticosteroids have been investigated as potential therapeutic interventions in COPD that may lower cardiovascular risk [7].

We aimed to evaluate the relationship between the blood pressure and inflammation, hypoxia, hypercapnia, and the severity of airway obstruction

\section{METHODS}

\section{Participants}

Seventy-five COPD patients who were diagnosed on the basis of the GOLD (Global Initiative for Chronic Obstructive Lung Disease) criteria. Forty-five healthy volunteers without any chronic disease were included in the control group. There was no difference between study and control group in terms of age and sex. Age, sex, body mass index (BMI), smoking history, CRP levels, 24-hour ambulatory blood pressure monitoring, arterial blood gas and respiratory function tests of the patient, and the control groups were recorded. We excluded the cases that had hypertension, angina pectoris, medical history of myocardial infarction, ST-T changes suggesting ischemic heart diseases, left bundle branch block pattern in electrocardiography, arrhythmias, current smokers, morbid obesity $\left(\mathrm{BMI}>30 \mathrm{~kg} / \mathrm{m}^{2}\right)$, renal disease, hyperthermia, and infection from the study.

\section{Laboratory analysis}

Blood samples were withdrawn for biochemical parameters (Beckman Coulter Inc., Indianapolis, IN, USA) and CRP (image brand name device, with nephelometric method). For arterial blood gas analyses, the patients ventilated room air for 30 minutes with fraction of inspired oxygen $\left(\mathrm{FiO}_{2}\right)$ 21\%; $2 \mathrm{~mL}$ of blood was withdrawn from the radial artery with injector washed with heparin. The analyzer for blood gases was used for the patient and control group. If oxygen saturation $\left(\mathrm{SO}_{2}\right)$ was 
< 90; it was defined as desaturated blood. The forced expiratory volume in 1 second $\left(\mathrm{FEV}_{1}\right)$ is a measure of how much air can be exhaled in one second following a deep inhalation. $\mathrm{FEV}_{1}$ value is an important part of classification COPD and monitoring progression of the condition. Respiratory function tests were done via dry type spirometry (VMax 2oC, SensorMedics, Yorba Linda, CA, USA). The association between $\mathrm{FEV}_{1} \%$ and ambulatory blood pressure was evaluated.

\section{Ambulatory blood pressure monitoring}

In all cases, ambulatory blood pressure measurements were done via a device with brand name of Mobil-OGraph (Mobil-O-Graph I.E.M GmbH, Stolberg, Germany). The measurements were evaluated as day time (6:00 AM to 9:59 PM) and night time (10:00 PM to 5:59 AM) with measurements done in every 30 minutes.

\section{Statistical analysis}

The statistical analyses were done via using SPSS version 19.0 (IBM Co., Armonk, NY, USA). Student $t$ test and Mann-Whitney U test, chi-square tests, and Pearson correlation analysis were used for statistical analyses. A $p$ value $<0.05$ assumed to be statistically significant. The data were given as means, median, standard deviation, case number, and percentage (\%).

\section{Etics}

The study was approved by the Cumhuriyet University Ethics Committee in Sivas, Turkey (2010-01/43). All participants were informed about the study and their informed consent was obtained. The study adhered to the tenets of the Declaration of Helsinki.

\section{RESULTS}

We enrolled 75 patients with COPD and 45 control cases into the study. The mean age of the study and the control groups were $63.8 \pm 7.4$ and $62.2 \pm 10.2$, respectively ( $p>0.05)$. In Table 1 , the blood pressure values of the two groups are given. In COPD patients, the night time systolic blood pressure (SBP), diastolic blood pressure (DBP), and pulse per minute, and the mean blood pressures readings were significantly elevated compared to the control group. Of the six variables only three were
Table 1. Demographic, inflammatory, and hemodynamic properties in the study groups

\begin{tabular}{|c|c|c|c|}
\hline Parameter & $\mathrm{COPD}(\mathrm{n}=75)$ & $\begin{array}{l}\text { Control } \\
(\mathrm{n}=45)\end{array}$ & $p$ value \\
\hline Sex, male/female & $25 / 50$ & $19 / 26$ & $0.48^{a}$ \\
\hline Age, yr & $63.8 \pm 7.4$ & $62.2 \pm 10.2$ & $0.34^{b}$ \\
\hline $\begin{array}{l}\text { Body mass index, } \\
\mathrm{kg} / \mathrm{m}^{2}\end{array}$ & $27.2 \pm 6.1$ & $27.7 \pm 4.0$ & $0.63^{b}$ \\
\hline CRP & $21.4 \pm 14.5$ & $5.4 \pm 2.5$ & $0.001^{b}$ \\
\hline $\begin{array}{l}\text { Day time SBP, } \\
\text { mmHg }\end{array}$ & $119.7 \pm 13.2$ & $117.8 \pm 7.0$ & $0.36^{\mathrm{b}}$ \\
\hline $\begin{array}{l}\text { Night time SBP, } \\
\text { mmHg }\end{array}$ & $117.4 \pm 13.6$ & $105.0 \pm 6.1$ & $0.001^{b}$ \\
\hline Total SBP, mmHg & $116.9 \pm 17.0$ & $113.6 \pm 7.6$ & $0.23^{\mathrm{b}}$ \\
\hline $\begin{array}{l}\text { Day time DBP, } \\
\text { mmHg }\end{array}$ & $73.3 \pm 8.2$ & $72.5 \pm 7 \cdot 3$ & $0.60^{b}$ \\
\hline $\begin{array}{l}\text { Night time DBP, } \\
\text { mmHg }\end{array}$ & $71.9 \pm 9.7$ & $68.1 \pm 7.0$ & $0.03^{b}$ \\
\hline Total DBP, mmHg & $72.5 \pm 7.9$ & $71.0 \pm 5.6$ & $0.30^{\mathrm{b}}$ \\
\hline $\begin{array}{l}\text { Day time pulse } \\
\text { pressure, } \mathrm{mmHg}\end{array}$ & $47.8 \pm 9.8$ & $42.4 \pm 6.5$ & $0.001^{b}$ \\
\hline $\begin{array}{l}\text { Night time pulse } \\
\text { pressure, } \mathrm{mmHg}\end{array}$ & $48.6 \pm 10.5$ & $41.6 \pm 7.0$ & $0.001^{b}$ \\
\hline $\begin{array}{l}\text { Total pulse pres- } \\
\text { sure, } \mathrm{mmHg}\end{array}$ & $47 \cdot 9 \pm 9 \cdot 3$ & $42.1 \pm 6.3$ & $0.001^{b}$ \\
\hline Total mean pulse & $88.3 \pm 14.3$ & $75.2 \pm 11.1$ & $0.001^{b}$ \\
\hline Day time pulse & $89.6 \pm 13.8$ & $78.3 \pm 12.0$ & $0.001^{b}$ \\
\hline Night time pulse & $86.7 \pm 16.3$ & $70.2 \pm 10.5$ & $0.001^{b}$ \\
\hline
\end{tabular}

Values are presented as mean \pm SD.

COPD, chronic obstructive pulmonary disease; CRP, C-reactive protein; SBP, systolic blood pressure; DBP, diastolic blood pressure.

${ }^{a}$ Chi-square test.

${ }^{\mathrm{b}}$ Student $t$ test.

statistically significant: day time SBP, night time SBP, total DBP (Table 2).

In Table 2, the association of blood pressure parameters with $\mathrm{FEV}_{1} \%, \mathrm{pH}$, partial pressure carbon dioxide $\left(\mathrm{PCO}_{2}\right)$, partial pressure oxygen $\left(\mathrm{PO}_{2}\right), \mathrm{SO}_{2}$, bicarbonate $\left(\mathrm{HCO}_{3}\right)$, and CRP levels with correlation analyses are given. In the correlation analysis, night time SBP was associated with all the parameters except $\mathrm{FEV}_{1} \%$. DBP was associated with $\mathrm{pH}$ and $\mathrm{HCO}_{3}$ levels parameters of blood gases. The mean night time, day time pulse pressures, and 24-hour pulse per minute values were also as- 
Table 2. The correlations of blood pressure variability parameters with blood gas and inflammation parameters and spirometry parameters

\begin{tabular}{|c|c|c|c|c|c|c|c|c|c|c|c|c|}
\hline \multirow{2}{*}{ Parameter } & \multicolumn{3}{|c|}{ SBP } & \multicolumn{3}{|c|}{ DBP } & \multicolumn{3}{|c|}{ Pulse } & \multicolumn{3}{|c|}{ Pulse pressure } \\
\hline & Day time & Night & $24 \mathrm{hr}$ & Day time & Night & $24 \mathrm{hr}$ & Day time & Night & $24 \mathrm{hr}$ & Day time & Night & $24 \mathrm{hr}$ \\
\hline \multicolumn{13}{|l|}{$\mathrm{FEV}_{1} \%$} \\
\hline$r$ & -0.05 & 0.03 & -0.10 & -0.13 & 0.01 & -0.11 & 0.02 & -0.02 & 0.03 & 0.07 & -0.00 & 0.03 \\
\hline$p$ value & 0.69 & 0.81 & 0.39 & 0.26 & 0.92 & 0.35 & 0.89 & 0.87 & 0.82 & 0.57 & 0.99 & 0.77 \\
\hline \multicolumn{13}{|l|}{$\mathrm{pH}$} \\
\hline$r$ & 0.08 & $0.46^{\mathrm{a}}$ & 0.11 & 0.05 & $0.20^{b}$ & 0.10 & $0.39^{\mathrm{a}}$ & $0.49^{\mathrm{a}}$ & $0.44^{\mathrm{a}}$ & $0.28^{\mathrm{a}}$ & $0.34^{\mathrm{a}}$ & $0.32^{\mathrm{a}}$ \\
\hline$p$ value & 0.37 & 0.001 & 0.23 & 0.60 & 0.03 & 0.30 & 0.001 & 0.001 & 0.001 & 0.001 & 0.001 & 0.001 \\
\hline \multicolumn{13}{|l|}{$\mathrm{PCO}_{2}$} \\
\hline$r$ & 0.12 & $0.45^{\mathrm{a}}$ & 0.13 & 0.04 & 0.16 & 0.08 & $0.36^{\mathrm{a}}$ & $0.46^{\mathrm{a}}$ & $0.40^{\mathrm{a}}$ & $0.33^{\mathrm{a}}$ & $0.36^{\mathrm{a}}$ & $0.36^{a}$ \\
\hline$p$ value & 0.18 & 0.001 & 0.15 & 0.66 & 0.07 & 0.38 & 0.001 & 0.001 & 0.001 & 0.001 & 0.001 & 0.001 \\
\hline \multicolumn{13}{|l|}{$\mathrm{PO}_{2}$} \\
\hline$r$ & 0.04 & $0.42^{\mathrm{a}}$ & 0.03 & -0.03 & 0.13 & 0.02 & $0.36^{\mathrm{a}}$ & $0.46^{\mathrm{a}}$ & $0.41^{\mathrm{a}}$ & $0.27^{\mathrm{a}}$ & $0.36^{\mathrm{a}}$ & $0.31^{\mathrm{a}}$ \\
\hline$p$ value & 0.67 & 0.001 & 0.76 & 0.74 & 0.16 & 0.87 & 0.001 & 0.001 & 0.001 & 0.001 & 0.001 & 0.001 \\
\hline \multicolumn{13}{|l|}{$\mathrm{SO}_{2}$} \\
\hline$r$ & 0.07 & $0.45^{\mathrm{a}}$ & 0.09 & 0.02 & 0.18 & 0.07 & $0.38^{\mathrm{a}}$ & $0.48^{\mathrm{a}}$ & $0.43^{\mathrm{a}}$ & $0.29^{\mathrm{a}}$ & $0.35^{\mathrm{a}}$ & $0.32^{\mathrm{a}}$ \\
\hline$p$ value & 0.47 & 0.001 & 0.34 & 0.81 & 0.05 & 0.46 & 0.001 & 0.001 & 0.001 & 0.001 & 0.001 & 0.001 \\
\hline \multicolumn{13}{|l|}{$\mathrm{HCO}_{3}$} \\
\hline$r$ & 0.09 & $0.46^{\mathrm{a}}$ & 0.10 & 0.04 & $0.19^{\mathrm{b}}$ & 0.09 & $0.35^{\mathrm{a}}$ & $0.48^{\mathrm{a}}$ & $0.41^{\mathrm{a}}$ & $0.31^{\mathrm{a}}$ & $0.36^{\mathrm{a}}$ & $0.34^{\mathrm{a}}$ \\
\hline$p$ value & 0.33 & 0.001 & 0.29 & 0.68 & 0.04 & 0.34 & 0.001 & 0.001 & 0.001 & 0.001 & 0.001 & 0.001 \\
\hline \multicolumn{13}{|l|}{ CRP } \\
\hline$r$ & 0.10 & $0.35^{\mathrm{a}}$ & 0.11 & -0.01 & 0.13 & 0.07 & $0.22^{\mathrm{b}}$ & $0.32^{\mathrm{a}}$ & $0.27^{\mathrm{a}}$ & $0.21^{b}$ & $0.21^{b}$ & $0.23^{\mathrm{b}}$ \\
\hline$p$ value & 0.26 & 0.001 & 0.23 & 0.90 & 0.17 & 0.47 & 0.02 & 0.001 & 0.001 & 0.02 & 0.02 & 0.01 \\
\hline
\end{tabular}

$\mathrm{SBP}$, systolic blood pressure; $\mathrm{DBP}$, diastolic blood pressure; $\mathrm{FEV}_{1}$, forced expiratory volume in 1 second; $\mathrm{PCO}_{2}$, partial pressure carbon dioxide; $\mathrm{PO}_{2}$, partial pressure oxygen; $\mathrm{SO}_{2}$, oxygen saturation; $\mathrm{HCO}_{3}$, bicarbonate; $\mathrm{CRP}$, C-reactive protein.

${ }^{\mathrm{a}}$ Correlation is significant at the 0.01 level (2-tailed), Pearson correlation analysis.

${ }^{\mathrm{b}}$ Correlation is significant at the 0.05 level (2-tailed).

Table 3. Blood pressure parameters according to degree of airway obstruction

\begin{tabular}{|c|c|c|c|c|}
\hline Parameter & Moderate $\operatorname{COPD}(n=4)$ & Severe COPD $(n=21)$ & Very severe $\operatorname{COPD}(\mathrm{n}=50)$ & $p$ value \\
\hline Day time SBP, mmHg & $129.5 \pm 11.6$ & $117.5 \pm 12.5$ & $119.9 \pm 13.6$ & 0.25 \\
\hline Night time SBP, mmHg & $132.8 \pm 4.9$ & $113.8 \pm 12.2$ & $117.6 \pm 13.8$ & $0.03^{\mathrm{a}}$ \\
\hline Total SBP, mmHg & $127 \cdot 3 \pm 4 \cdot 6$ & $111.5 \pm 24.5$ & $118.3 \pm 13.0$ & 0.17 \\
\hline Day time DBP, $\mathrm{mmHg}$ & $74.0 \pm 12.0$ & $71.1 \pm 7.9$ & $74.1 \pm 8.1$ & 0.26 \\
\hline Night time DBP, mmHg & $79.8 \pm 2.2$ & $68.7 \pm 8.8$ & $72.6 \pm 10.1$ & 0.06 \\
\hline Total DBP, mmHg & $73.5 \pm 3.0$ & $70.2 \pm 7.8$ & $73.3 \pm 8.1$ & 0.32 \\
\hline Day time pulse pressure, $\mathrm{mmHg}$ & $85.5 \pm 10.3$ & $90.9 \pm 17.4$ & $89.4 \pm 12.5$ & 0.84 \\
\hline Night time pulse pressure, $\mathrm{mmHg}$ & $84.0 \pm 13.4$ & $87.9 \pm 21.4$ & $86.5 \pm 14.1$ & 0.91 \\
\hline Total pulse pressure, $\mathrm{mmHg}$ & $84.8 \pm 11.6$ & $90.0 \pm 18.2$ & $87.9 \pm 12.8$ & 0.92 \\
\hline Total mean pulse & $53.8 \pm 4.6$ & $48.2 \pm 8.3$ & $47 \cdot 3 \pm 10.0$ & 0.29 \\
\hline Day time pulse & $54 \cdot 3 \pm 4 \cdot 4$ & $47.9 \pm 8.8$ & $47.2 \pm 10.5$ & 0.26 \\
\hline Night-time pulse & $53.1 \pm 6.1$ & $50.9 \pm 11.8$ & $47 \cdot 3 \pm 10.1$ & 0.42 \\
\hline
\end{tabular}

Values are presented as mean $\pm \mathrm{SD}$.

COPD, chronic obstructive pulmonary disease; SBP, systolic blood pressure; DBP, diastolic blood pressure.

${ }^{\text {a }}$ Statistically significant. 
sociated with all the parameters except $\mathrm{FEV}_{1} \%$.

In Table 3, the means of blood pressure parameters according to the degree of airway obstruction were given. We had no patients in mild COPD group (Stage 1). Only the night time SBP was statistically different in terms of blood pressure parameters among the groups.

\section{DISCUSSION}

In our study, we excluded the cases with hypertension, heart disease, renal disease, and patients with obesity. In the ambulatory blood pressure monitoring measurements, we objected to find the difference in changes in the daily rhythm of SBP and DBP and the causative factors. Though the study cases were normotensives their mean blood pressures and pulse pressures and per minute pulse rates were significantly higher compared to the control group.

COPD patients show a high prevalence of cardiovascular disease, higher than expected given their age and the coexistence of classic cardiovascular risk factors [8]. Several studies have demonstrated associations between COPD and abnormalities of systemic vascular dysfunction $[9,10]$. This is a very complex interaction. Patients with COPD are subject to intermittent hypoxia (for example with exercise, or during exacerbations), and at a later stage of the disease, sustained hypoxia. Hypoxia has profound effects on the cardiovascular system. This is also an area of particular relevance in obstructive sleep apnea, a condition with intermittent hypoxia, which is, associated with increased risk of hypertension, type 2 diabetes, angina and myocardial infarction, stroke and fatal cardiovascular events [11]. In a study by Cui et al. [12], the reported prevalence of CVD in COPD patients was $51.7 \%$. The three most prevalent cardiovascular diseases were ischemic heart disease (28.9\%), heart failure (19.6\%), and arrhythmia (12.6\%).

In cases with COPD late term hypoxia is a frequently encountered condition. Hypoxia causes an increase in pulse rate and SBP [13]. In COPD chronic hypoxia in turn causes hypertension. Hypertension is not only a well established cardiovascular risk factor but also increases the risk of atherosclerosis. Both clinical and experimental data show that high blood pressure enhances the development of atherosclerosis $[14,15]$. Changes in endothelial function and morphology are also cardinal features of hypertension.

Chronic intermittent hypoxia can cause increased blood pressure and sympathetic activity in rats, and the effect was dependent on the degree of hypoxia and the time of exposure. The results suggested that chronic intermittent hypoxia induced higher blood pressure was associated with increased sympathetic activity [16]. In a study conducted by Yasuma and Hayano [17], heart rate, mean arterial pressure, respiratory rate, and tidal volume increased with progressive hypoxia.

Sleep has significant effects on respiration, even in healthy subjects. During sleep, chemoreceptor sensitivity decreases, respiratory motor output, and muscle contraction diminish, ventilation/perfusion (V/Q) relationships alter, and airflow resistance increases. The net effect of these changes is relative alveolar hypoventilation, which is particularly pronounced in rapid eye movement sleep. While clinically unimportant in otherwise healthy individuals, these changes can lead to significant nocturnal hypoxemia in patients with COPD [18]. This results hypercapnia and decreased $\mathrm{O}_{2}$ saturation in the patients. The principal contributor to hypoxemia in COPD patients is V/Q mismatch resulting from progressive airflow limitation and emphysematous destruction of the pulmonary capillary bed [19]. Wan et al. [16] stated that there increased sympathetic activity due to hypoxia in COPD patients. Nocturnal hypoxemia in COPD is common. Also we showed that the variables examined in the study affected the night time blood pressure parameters [18]. In this study, the regression model revealed a strong association between hypoxia and COPD. We think that hypoxia has an important role in the factors that have an effect on blood pressure, pulse pressure, and pulse per minute.

In our study, there was a positive correlation between $\mathrm{PO}_{2}$ and $\mathrm{SBP}$, pulse and pulse pressure in COPD group. SBP, pulse and pulse rate were also falling when hypoxia. Although this seems contradictory, may be explained by the early and late differentiation of the cardiovascular response to hypoxia. Cowburn et al. [20] reported in their study that an increase of $20 \mathrm{mmHg}$ in SBP and DBP occurred with increased ventilation and hypoxic pressure reflex in the first 10 to 15 minutes as a hypoxia response. Following this brief response, they reported a $12 \%$ decrease in systemic blood pressure. It reported that heart 
rate increased in the first 13 minutes and decreased 53\% after 120 minutes. Since the average of the parameters was evaluated in our study, these values indicate a late term response. In the late period hypoxia and blood pressure parameters showed a positive correlation.

The relationship between COPD and cardiovascular disease were investigated in many studies. In a study conducted in Beijing hypertension prevalence were found to be $37.7 \%$ and $46.8 \%$ in male and female COPD patients respectively [12]. The study group had higher SBP and DBP, pulse pressures and pulse per minute compared to the control group.

Hypertension is not only a well established cardiovascular risk factor but also increases the risk of atherosclerosis. Clinical trials have shown that, in the highest quintile of DBP, even with the added risks of high cholesterol and smoking, hypertension still contributes significantly to risk for atherosclerosis $[14,21]$. Atherosclerosis is a disease that occurs due to lipid metabolism disorders and accumulation of lipid particles in the vessel walls. It is also considered as an inflammatory disease [22]. Inflammation also has a role in the pathogenesis of COPD. Fabbri and Rabe [23] has considered COPD as a chronic systemic inflammatory syndrome. A number of inflammatory markers have been shown to be elevated systemically in COPD including interleukin 6 (IL-6), IL-8, tumor necrosis factor $\alpha$, and fibrinogen [24-26]. Hypoxia has been shown to have a number of effects that influence atherogenesis, and it seems likely that these effects are multifactorial. These include increased inflammation, oxidative stress, up regulation of cell surface adhesion molecules and hemodynamic stress [27-30].

Hartmann et al. [28] has shown that hypoxic and hyperbaric conditions cause significant increases in CRP levels. CRP is an acute phase protein synthesized predominantly by the hepatocytes in response to tissue damage or inflammation. It reflects the total systemic burden of inflammation of individuals [31]. The severity of COPD and CRP levels is associated with each other [32,33]. In vitro studies showed that CRP binds low density lipoprotein, very low density lipoprotein, and activates complement. Then macrophages stimulate tissue factor production and hence coagulation. Also, CRP stimulate expression of adhesion molecules intercellular adhesion molecule 1 (ICAM-1), vascular cell adhesion molecule 1 (VCAM-1) and E-selectin and increase monocyte and lymphocyte infiltration. This also shows the association CRP "a marker of vascular inflammation" and cardiovascular disease [34].

Jialal and Devaraj [35] stated in their study that high-sensitivity CRP is clearly a risk marker, and data are evolving to suggest that CRP also might be proatherogenic. In another study it was demonstrated that people with high CRP levels had impaired endothelial vasoreactivity [34].

The previous studies reported that CRP levels are elevated in patients with hypertension compared to the control groups [36]. De Haro et al. [37] reported that plasma levels of CRP are associated not only with the presence of atherosclerosis but also with its clinical severity. Gan et al. [38] reported that active cigarette smoking and poor $\mathrm{FEV}_{1} \%$ had an additive effect on systemic markers of inflammation. Individually, active smoking and reduced $\mathrm{FEV}_{1} \%$ were associated with 1.6 and 2.3 increased odds of elevated CRP, respectively. For individuals with both of these risk factors, the odds increased by 3.3-fold, indicating an additive response [38]. In this study, the cases with COPD had higher mean SBP and DBP compared to the control group. When blood pressure parameters were evaluated according to the degree of COPD, statistical difference was found only in terms of night time SBP. In accordance with our work, Fan et al. [39] reported a statistically significant difference between the level of COPD and the SBP in their study.

We showed that an association exists between the CRP levels and blood and pulse pressure parameters. This is also consistent with the work of Wan et al. [16]. COPD is associated with significant cardiovascular mortality. There are studies that examine the relationship between $\mathrm{FEV}_{1} \%$ and cardiovascular disease. However, its relationship with change of blood pressure and pulse has not been studied much. Schunemann et al. [40] suggest that $\mathrm{FEV}_{1} \%$ is a risk factor for all cause and ischemic heart disease mortality for a follow-up period of 29 years after adjustment for other risk factors. As a continuous variable, $\mathrm{FEV}_{1} \%$ was a significant predictor of ischemic heart disease mortality in both men and women. In this study, we did not find an association between $\mathrm{FEV}_{1} \%$ and the parameters of blood and pulse pressure.

Our study had limitations which must be taken into consideration. Regarding Table 1, persons who had nor- 
mal pulmonary function tests and arterial gas parameters were included in the control group. Since these values were not stored in our database and this comparison could not be made. The number of patients in the moderate group is not sufficient in our study $(n=4)$. This should be taken into consideration when assessing blood pressure parameters according to the degree of COPD.

As a result, we think that airflow limitation is independent from the changes of blood and pulse pressure changes. COPD is not a disease that only affects the lungs but also other systems like cardiovascular system and can be nominated as a systemic inflammatory disease when causative factor and the complications are considered. In this study, we in COPD patients found that parameters of SBP and DBP and pulse pressures were significantly elevated compared to the control groups in COPD patients. This in turn may cause understanding of the pathophysiology of COPD and its complications. In this study, the regression model revealed association between day time SBP, night time SBP, total DBP, and COPD. We think that hypoxia and inflammation may have an important role in the factors that have an effect on blood pressure dynamics. Further multicenter clinical trials, including a higher number of patients on this subject, which will evaluate the effect of hypoxia and inflammation on blood pressure parameters are needed.

\section{KEY MESSAGE}

1. Hypoxia and inflammation may have an important role on blood pressure dynamics.

2. Systolic blood pressure and diastolic blood pressure and pulse pressures were significantly higher compared to the healthy volunteers in chronic obstructive pulmonary disease (COPD) patients.

3. This in turn may cause understanding of the pathophysiology of COPD's cardiovascular system complications.

\section{Conflict of interest}

No potential conflict of interest relevant to this article was reported.

\section{REFERENCES}

1. MacNee W. Systemic inflammatory biomarkers and co-morbidities of chronic obstructive pulmonary disease. Ann Med 2013;45:291-300.

2. Dahl M, Vestbo J, Lange P, Bojesen SE, Tybjaerg-Hansen A, Nordestgaard BG. C-reactive protein as a predictor of prognosis in chronic obstructive pulmonary disease. Am J Respir Crit Care Med 2007;175:250-255.

3. de Torres JP, Cordoba-Lanus E, Lopez-Aguilar C, et al. C-reactive protein levels and clinically important predictive outcomes in stable COPD patients. Eur Respir J 2006;27:902-907.

4. Barnes PJ, Celli BR. Systemic manifestations and comorbidities of COPD. Eur Respir J 2009;33:1165-1185.

5. Vestbo J, Hurd SS, Agusti AG, et al. Global strategy for the diagnosis, management, and prevention of chronic obstructive pulmonary disease: GOLD executive summary. Am J Respir Crit Care Med 2013;187:347-365.

6. Sinden NJ, Stockley RA. Chronic obstructive pulmonary disease: an update of treatment related to frequently associated comorbidities. Ther Adv Chronic Dis 2010;1:43-57.

7. Ghoorah K, De Soyza A, Kunadian V. Increased cardiovascular risk in patients with chronic obstructive pulmonary disease and the potential mechanisms linking the two conditions: a review. Cardiol Rev 2013;21:196-202.

8. de Lucas-Ramos P, Izquierdo-Alonso JL, Rodriguez-Gonzalez Moro JM, et al. Chronic obstructive pulmonary disease as a cardiovascular risk factor. Results of a case-control study (CONSISTE study). Int J Chron Obstruct Pulmon Dis 2012;7:679-686.

9. Jenkins PC. The relationship between dyspnea and blood pressure in chronic obstructive pulmonary disease. J Cardiovasc Nurs 2007;22:351-358.

10. Maclay JD, McAllister DA, Macnee W. Cardiovascular risk in chronic obstructive pulmonary disease. Respirology 2007;12:634-641.

11. Somers VK. Sleep: a new cardiovascular frontier. N Engl J Med 2005;353:2070-2073.

12. Cui H, Miao DM, Wei ZM, et al. Prevalence of cardiovascular disease in subjects hospitalized due to chronic obstructive pulmonary disease in Beijing from 2000 to 2010. J Geriatr Cardiol 2012;9:5-10.

13. Xie A, Skatrud JB, Puleo DS, Morgan BJ. Exposure to hypoxia produces long-lasting sympathetic activation in humans. J Appl Physiol (1985) 2001;91:1555-1562. 
14. Kannel WB, Neaton JD, Wentworth D, et al. Overall and coronary heart disease mortality rates in relation to major risk factors in 325,348 men screened for the MRFIT. Multiple Risk Factor Intervention Trial. Am Heart J 1986;112:825-836.

15. Alexander RW. Theodore Cooper Memorial Lecture. Hypertension and the pathogenesis of atherosclerosis. Oxidative stress and the mediation of arterial inflammatory response: a new perspective. Hypertension 1995;25:155-161.

16. Wan NS, Chen BY, Feng J, et al. The effects of chronic intermittent hypoxia on blood pressure and sympathetic nerve activity in rats. Zhonghua Jie $\mathrm{He} \mathrm{He} \mathrm{Hu} \mathrm{Xi}$ Za Zhi 2012;35:29-32.

17. Yasuma F, Hayano JI. Impact of acute hypoxia on heart rate and blood pressure variability in conscious dogs. Am J Physiol Heart Circ Physiol 2000;279:H2344-H2349.

18. McNicholas WT. Impact of sleep in COPD. Chest 2000; $117(2$ Suppl):48S-53S.

19. Kent BD, Mitchell PD, McNicholas WT. Hypoxemia in patients with COPD: cause, effects, and disease progression. Int J Chron Obstruct Pulmon Dis 2011;6:199-208.

20. Cowburn AS, Macias D, Summers C, Chilvers ER, Johnson RS. Cardiovascular adaptation to hypoxia and the role of peripheral resistance. Elife 2017;6:e28755.

21. Stamler J, Neaton JD, Wentworth DN. Blood pressure (systolic and diastolic) and risk of fatal coronary heart disease. Hypertension 1989;13(5 Suppl):I2-I12.

22. Ross R. Atherosclerosis: an inflammatory disease. N Engl J Med 1999;340:115-126.

23. Fabbri LM, Rabe KF. From COPD to chronic systemic inflammatory syndrome? Lancet 2007;370:797-799.

24. Schols AM, Buurman WA, Staal van den Brekel AJ, Dentener MA, Wouters EF. Evidence for a relation between metabolic derangements and increased levels of inflammatory mediators in a subgroup of patients with chronic obstructive pulmonary disease. Thorax 1996;51:819-824.

25. Gan WQ, Man SF, Senthilselvan A, Sin DD. Association between chronic obstructive pulmonary disease and systemic inflammation: a systematic review and a meta-analysis. Thorax 2004;59:574-580.

26. Palange P, Testa U, Huertas A, et al. Circulating haemopoietic and endothelial progenitor cells are decreased in COPD. Eur Respir J 2006;27:529-541.

27. Lattimore JD, Wilcox I, Nakhla S, Langenfeld M, Jessup W, Celermajer DS. Repetitive hypoxia increases lipid loading in human macrophages-a potentially atherogenic effect.
Atherosclerosis 2005;179:255-259.

28. Hartmann G, Tschop M, Fischer R, et al. High altitude increases circulating interleukin-6, interleukin-1 receptor antagonist and C-reactive protein. Cytokine 2000;12:246-252.

29. Savransky V, Nanayakkara A, Li J, et al. Chronic intermittent hypoxia induces atherosclerosis. Am J Respir Crit Care Med 2007;175:1290-1297.

30. Chen L, Einbinder E, Zhang Q, Hasday J, Balke CW, Scharf SM. Oxidative stress and left ventricular function with chronic intermittent hypoxia in rats. Am J Respir Crit Care Med 2005;172:915-920.

31. Pepys MB, Hirschfield GM. C-reactive protein: a critical update. J Clin Invest 2003;111:1805-1812.

32. Sin DD, Lacy P, York E, Man SF. Effects of fluticasone on systemic markers of inflammation in chronic obstructive pulmonary disease. Am J Respir Crit Care Med 2004;170:760-765.

33. Pinto-Plata VM, Mullerova H, Toso JF, et al. C-reactive protein in patients with COPD, control smokers and non-smokers. Thorax 2006;61:23-28.

34. Fichtlscherer S, Rosenberger G, Walter DH, Breuer S, Dimmeler S, Zeiher AM. Elevated C-reactive protein levels and impaired endothelial vasoreactivity in patients with coronary artery disease. Circulation 2000;102:10001006.

35. Jialal I, Devaraj S. Inflammation and atherosclerosis: the value of the high-sensitivity C-reactive protein assay as a risk marker. Am J Clin Pathol 2001;116 Suppl:S108-S115.

36. Dodson PM, Shine B. Retinal vein occlusion: C-reactive protein and arterial hypertension. Acta Ophthalmol (Copenh) 1984;62:123-130.

37. De Haro J, Acin F, Medina FJ, Lopez-Quintana A, March JR. Relationship between the plasma concentration of C-reactive protein and severity of peripheral arterial disease. Clin Med Cardiol 2008;3:1-7.

38. Gan WQ, Man SF, Sin DD. The interactions between cigarette smoking and reduced lung function on systemic inflammation. Chest 2005;127:558-564.

39. Fan W, Lee H, Lee A, Kieu C, Wong ND. Association of lung function and chronic obstructive pulmonary disease with American Heart Association's Life's Simple 7 cardiovascular health metrics. Respir Med 2017;131:85-93.

40. Schunemann HJ, Dorn J, Grant BJ, Winkelstein W Jr, Trevisan M. Pulmonary function is a long-term predictor of mortality in the general population: 29-year follow-up of the Buffalo Health Study. Chest 2000;118:656-664. 